\title{
Editorial
}

\section{Natural/Unconventional Computing and Its Philosophical Significance}

\section{Gordana Dodig Crnkovic ${ }^{1, *}$ and Raffaela Giovagnoli ${ }^{2}$}

1 Department of Computer Science and Networks, School of Innovation, Design and Engineering Mälardalen University, Västerås 721 23, Sweden

2 Department of Philosophy, Lateran University, Vatican City, Rome 00184, Italy; E-Mail: raffa.giovagnoli@tiscali.it

* Author to whom correspondence should be addressed; E-Mail: gordana.dodig-crnkovic@mdh.se; Tel.: +46-21-15-17-25.

Received: 31 October 2012; in revised form: 21 November 2012 / Accepted: 26 November 2012 / Published: 27 November 2012

\begin{abstract}
In this special issue we present a selection of papers from the Symposium on Natural/Unconventional Computing and its Philosophical Significance, held during the AISB/IACAP 2012 World Congress in Birmingham (UK). This article is an editorial, introducing the special issue of the journal with the selected papers and the research program of Natural/Unconventional Computing.
\end{abstract}

Keywords: natural computing; unconventional computing; computation beyond the Turing limit; unconventional models of computation

\section{Introduction}

The AISB/IACAP 2012 World Congress combined the British Society for the Study of Artificial Intelligence and the Simulation of Behaviour (AISB) convention and the International Association for Computing and Philosophy (IACAP) conference honoring Alan Turing's essential impact on the theory of computation, AI and philosophy of computing. The Congress was one of the events of the Alan Turing Year.

Even though Turing is best known for his Logical Machine (the Turing machine) and the Turing test of a machine's ability to exhibit intelligent behavior, his contribution to the foundations of 
computation is significantly broader in scope. He was among the first to pursue what Denning calls "computing as natural science" [1], and thus Hodges [2] describes Turing as a natural philosopher:

"He thought and lived a generation ahead of his time, and yet the features of his thought that burst the boundaries of the 1940s are better described by the antique words: natural philosophy."

This side of Turing's work was of special interest for the symposium investigating computational views of nature. The symposium addressed the following topics in two dedicated tracks:

(I) NATURAL/UNCONVENTIONAL COMPUTING — addressing the emerging paradigm of natural computing and its philosophical consequences with different aspects including: theoretical and philosophical views of natural/unconventional computing (such as understanding of computational processes in nature and in the human mind); characterization of the differences between conventional and unconventional computing; recent advances in natural computation such as computation found in nature, including organic computing; computation performed by natural materials; and computation inspired by nature; computation and its interpretation in a broader context of possible frameworks for modeling and implementation.

(II) REPRESENTATION AND COMPUTATIONALISM - highlighting the relevance of the relationship between human representation and machine representation with the analysis of the main issues concerning the contrast between symbolic representation/processing on the one hand and natureinspired, non-symbolic forms of computation on the other hand, with a special focus on connectionism. Particular developments that papers addressed were, among others: The embedded, embodied, and enactive approach to cognitive science; the dynamic systems approach; other representational possibilities: no representations or minimal representations and process/procedural representations.

\section{Delineation of the Field of Natural/Unconventional Computing}

Rozenberg et al. in The Handbook of Natural Computing [3] delineate Natural Computing as "the field of research that investigates both human-designed computing inspired by nature and computing taking place in nature." In particular, it includes [3]:

- Computational models inspired by natural systems such as neural computation, evolutionary computation, cellular automata, swarm intelligence, artificial immune systems, artificial life systems, membrane computing and amorphous computing.

- Computation performed by natural materials such as bioware in molecular computing or quantum-mechanical systems in case of quantum computing.

- Study of computational nature of processes taking place in (living) nature, such as: self-assembly, developmental processes, biochemical reactions, brain processes, bionetworks and cellular processes.

The symposium on Natural/Unconventional Computing and its Philosophical Significance presented a variety of studies ranging from computation-theoretical, physical, mathematical, biological, cognitive, scientific-theoretical and philosophical topics addressed by Cooper; Goyal; Phillips; Basti; Zenil; Lindley; Arriola-Rios, Demery, Wyatt, Sloman and Chappell; Bull, Holley, De Lacy Costello and Adamatzky; Menant; Burgin and Dodig Crnkovic; Hernández-Quiroz and Padilla; 
Hernandez-Espinosa; Franchette; Douglas; Giovagnoli and Schroeder, collected in the book Computing Nature [4], forthcoming in the Springer SAPERE book series.

\section{Contributions to the Special Issue}

"What led to this hope for this new kind of foundation for the laws of physics was really the quantum theory of computation." David Deutsch [5].

This special issue presents a selection of papers that place nicely into the info-computational framework where information is the basic structure while computation is the dynamics of the physical universe [6]. Information and computation exist in tandem, and they are studied as such in [7].

Even though there is no information without physical substrate, information is not the substrate. The central characteristics of information is that it propagates through a variety of substrates and still retains its content that for the receiver is a message about something absent, as Terrence Deacon aptly describes it in [8], or that indicates the presence of indirect existence, according to Kun $\mathrm{Wu}$ [9].

However simple this info-computational scheme might appear, there is a rich structure below the surface. As Kun $\mathrm{Wu}$ discusses the essence of the concept of information, he arrives to the conclusion that it is necessary to distinguish between three fundamental kinds of information:

"(I)nformation is shown to include three basic forms: In-itself, for-itself and regenerated information, which is constituted by the first two. Information in these three basic forms establishes the essence of information which is further developed in a fourth form-social information."

The distinction between the in-itself and the for-itself originate in the Kantian distinction between the world as it is in itself, and the world as it appears for us. This world in-itself in [6] is termed protoinformation, that becomes information for an agent capable of registering/memorizing and making use of it (building its own structures and behaviors on it). Unlike Kant and Kun Wu, who present a humancentric ontology, the present day AI, robotics and AL go beyond human agents and generalize information processing agents to much simpler entities. Back to David Deutsch:

"The way to get this substrate independence of information is to refer it to a level of physics that is below and more fundamental than things like laws of motion, that we have been used thinking of as near the lowest, most fundamental level of physics. Constructor theory is that deeper level of physics, physical laws and physical systems, more fundamental than the existing prevailing conception of what physics is (namely particles and waves and space and time and an initial state and laws of motion that describe the evolution of that initial state). " [5]

In this special issue, Giulio Chiribella, G. M. D'Ariano and P. Perinotti argue for quantum theory as the theory where information and physics meet. The connection to the work of Deutsch goes through understanding of computation as information processing.

Hector Zenil, Carlos Gershenson, James Marshall and David Rosenblueth contribute with a study of life as thermodynamic evidence of algorithmic structure. Even though algorithmic computation may remind us of classical approaches to computation, in biology information processing (computation) is a new way of approaching living systems. The contribution by Gordana Dodig Crnkovic and Mark Burgin on unconventional algorithms and complementarity of axiomatics and constructionism brings 
to the fore the limitations of our current mathematical apparatus and its necessary development in the direction suitable for the modeling of open, context-dependent frameworks which are necessary for modeling of living systems.

Andrée Ehresmann presents an info-computational model for (neuro-)cognitive systems on several levels of organization, based on the formalism of category theory.

Susan Stepney's contributions to the foundations of the research field of Natural/Unconventional Computing $[10,11]$ are widely recognized, and in this special issue she goes one step further from the modeling and simulation of natural systems and addresses the topic of unconventional computer programming.

In sum, the research field of natural/unconventional computing holds promise for bringing clarity and structure in a variety of research fields - from fundamental physics, to biology, cognitive science, neuroscience, medicine, sociology, sciences of complexity, information science, theory of computation and more. We hope with this special issue to have contributed by a few determined steps on the long journey exploring the landscape of non-classical computation.

\section{Acknowledgments}

The editors would like to thank Mark Burgin, Susan Stepney, Giulio Chiribella, Andrée Ehresmann, and Hector Zenil for their excellent collaboration.

\section{References and Notes}

1. Denning P.J. Computing is a natural science. Commun. ACM 2007, 50, 13-18.

2. Hodges, A. Turing: A Natural Philosopher; Phoenix: London, UK, 1997.

3. Rozenberg, G., Bäck, T., Kok, J.N., Eds. Handbook of Natural Computing, Volume II; Springer: Berlin Heidelberg, Germany, 2011.

4. Dodig-Crnkovic, G., Giovagnoli, R., Eds. Computing Nature: A Network of Networks of Concurrent Information Processes, SAPERE book series, forthcoming; Springer: Heidelberg, Germany. Available online: http://arxiv.org/abs/1210.7784 (accessed on 28 October 2012).

5. Constructor Theory, A Conversation with David Deutsch, Edge. Available online: http://www.edge.org/conversation.php?cid=constructor-theory (accessed on 28 October 2012).

6. Dodig-Crnkovic, G.; Müller, V. A Dialogue Concerning Two World Systems: Info-Computational vs. Mechanistic. Book Chapter in Information and Computation, Series in Information Studies; Dodig-Crnkovic, G., Burgin, M., Eds.; World Scientific Publishing Co.: Singapore, 2011. Available online: http://arxiv.org/abs/0910.5001 (accessed on 28 October 2012).

7. Dodig-Crnkovic, G., Burgin, M., Eds. Information and Computation, Series in Information Studies; World Scientific Publishing Co.: Singapore, 2011.

8. Deacon, T. Incomplete Nature: How Mind Emerged from Matter; W.W. Norton \& Company: New York, NY, USA, 2011.

9. $\mathrm{Wu}, \mathrm{K}$. The Essence, Classification and Quality of the Different Grades of Information. Information 2012, 3, 403-419. 
10. Stepney, S.; Braunstein, S.L.; Clark, J.A.; Tyrrell, A.; Adamatzky, A.; Smith, R.E.; Addis, T.; Johnson, C.; Timmis, J.; Welch, P.; et al. Journeys in Non-Classical Computation I: A Grand Challenge for Computing Research. Int. J. Parallel Emerg. Distr. Syst. 2005, 20, 5-19.

11. Stepney, S.; Braunstein, S.L.; Clark, J.A.; Tyrrell, A.; Adamatzky, A.; Smith, R.E.; Addis, T.; Johnson, C.; Timmis, J.; Welch, P.; et al. Journeys in Non-Classical Computation II: Initial Journeys and Waypoints. Int. J. Parallel Emerg. Distr. Syst. 2006, 21, 97-125.

(C) 2012 by the authors; licensee MDPI, Basel, Switzerland. This article is an open access article distributed under the terms and conditions of the Creative Commons Attribution license (http://creativecommons.org/licenses/by/3.0/). 